\title{
Compression Therapy: Clinical and Experimental Evidence
}

Hugo Partsch, MD, PhD

\begin{abstract}
Aim: A review is given on the different tools of compression therapy and their mode of action.
Methods: Interface pressure and stiffness of compression devices, alone or in combination can be measured in vivo. Hemodynamic effects have been demonstrated by measuring venous volume and flow velocity using MRI, Duplex and radioisotopes, venous reflux and venous pumping function using plethysmography and phlebodynamometry. Oedema reduction can be measured by limb volumetry.

Results: Compression stockings exerting a pressure of $\sim 20 \mathrm{mmHg}$ on the distal leg are able to increase venous blood flow velocity in the supine position and to prevent leg swelling after prolonged sitting and standing. In the upright position, an interface pressure of more than $50 \mathrm{mmHg}$ is needed for intermittent occlusion of incompetent veins and for a reduction of ambulatory venous hypertension during walking. Such high intermittent interface pressure peaks exerting a "massaging effect" may rather be achieved by short stretch multilayer bandages than by elastic stockings.

Conclusion: Compression is a cornerstone in the management of venous and lymphatic insufficiency. However, this treatment modality is still underestimated and deserves better understanding and improved educational programs, both for patients and medical staff.
\end{abstract}

Keywords: compression stockings, compression bandages, compression pressure, stiffness

$\mathrm{C}$ ompression therapy entailing the application of pressure to the lower extremities is a fundamental component in the management of chronic venous and lymphatic disease. Its main function is to counteract gravity which is a key factor for the disturbance of venous and lymphatic return from the lower extremity.

\section{BANDAGES}

Long stretch bandages expand over $100 \%$ of their original length. In contrast, short-stretch bandages stretch to less than 100\% and Zinc paste bandages (Unna's boot) have practically no extensibility ${ }^{1,2)}$ (Fig. 1).

\section{The Medical University of Vienna, Austria}

Received: August 8, 2012; Accepted: August 9, 2012

Corresponding author: Hugo Partsch, MD, PhD. Steinhäusl 126,

3033 Altlengbach, Austria

Tel: +0043-6641437274

E-mail: Hugo.Partsch@meduniwien.ac.at

*Invited Presentation at the 32th Annual Meeting of Japanese Society of Phlebology in Saitama, Japan, in June 2012.
Today mainly multicomponent bandages are used which are characterized by high stiffness, even when the single components are long stretch (see Fig. 3).

\section{Medical Compression Hosiery}

Medical compression stockings are made of elasticated textile. According to their length they are classified as knee-length, thigh-length and tights (panty style). They may be custom made or off the shelf, available in standard sizes.

According to the exerted pressure, different compression classes are available. The pressure profile of each compression class varies among different countries and is measured by a variety of laboratory methods. ${ }^{1,2)}$ Therefore, it has been proposed to classify the strength of compression stockings by declaring their pressure ranges exerted on the distal leg and not by using "compression classes". ${ }^{3)}$ 


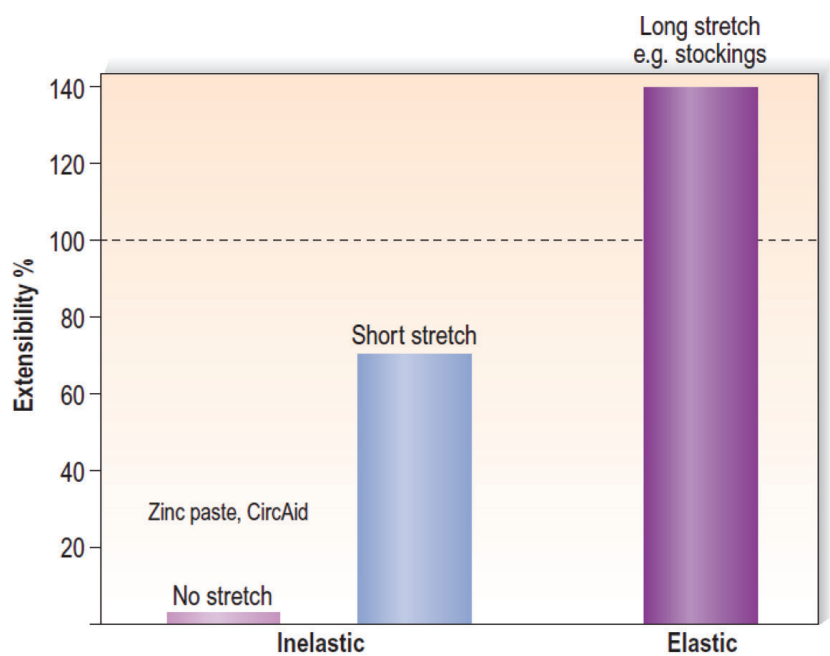

Fig. 1 Differentiation of elastic and inelastic compression material based on the maximal extensibility of the textile. Material with a maximal stretch of less than $100 \%$ is called "inelastic", either "non-stretch" (e.g. zinc paste) or "short stretch". Material extending more than $100 \%$ is defined as "long stretch".

\section{Intermittent Pneumatic Pressure (IPC) Pumps}

IPC devices consist of single or preferably multiple, inelastic cuffs that are intermittently and/or sequentially inflated. The chambers are applied around the extremity which is pumped up to different pressure levels in various time intervals. A broad variety of pumps is on the market. These pumps are not only indicated to prevent thrombosis in a patient after surgery but provide also a very useful supplement to conventional compression therapy, especially in patients with lymphoedema, restricted walking ability and with arterial problems.

\section{Other Compression Devices}

Velcro devices (CircAid $囚)$, special compression stockings like Tubulcus ${ }^{\circledR}$, double stockings like Mediven ulcer kit ${ }^{\circledR}$, but also foam and rubber pads like e.g. medi postop ${ }^{\circledR}$ to achieve an increase of local pressure by eccentric compression, expanding our therapeutic armamentarium.

\section{Measurement of Interface Pressure and STIFFNESS IN Vivo}

There is a need for a standardized measurement of interface pressures and fabric stiffness in vivo allowing for comparison between different compression systems, both for the provision of clinical service and research.4) Fabric stiffness is determined by the increase of interface pressure per centimetre increase of the leg segment due to muscular contraction during walking or standing. For equal resting pressures, the peak pressure and bandwidth of pressure changes at the ankle is much higher with short stretch material. The addition of several layers of compression bandages and the superimposition of stockings does not only increase the interface pressure but also the stiffness of the cumulative compression (Fig. 2). ${ }^{5}$ )

\section{Mannequin Leg to Assess Stiffaness}

Hirai and coworkers have developed a leg model whose circumference can be extended by one centimetre. $\left.{ }^{6}\right)$ The increase of the pressure under a compression device on a specific leg point, e.g. at B1 corresponds to the stiffness of the material. Figure 3 shows some results from experiments with the mannequin leg, comparing pressure and stiffness of different compression stockings and bandages on this model. As can be seen the main difference between stockings and bandages is not the resting pressure (x-axis), but the stiffness (y-axis) which is significantly higher for multicomponent bandages than for stockings.

\section{Practical Use of Bandages}

Table 1 shows the pressure ranges on the distal lower leg agreed in a consensus meeting. ${ }^{5)}$

The main indications for bandages are situated in a pressure range above $40 \mathrm{mmHg}$ in the upright position which can only exceptionally be reached by medical compression stockings. Examples are severe leg ulcers, massively swollen and painful legs in the acute stage of deep and superficial thrombosis, and lymphoedema. ${ }^{3)}$ In order to achieve compression pressures, which are high enough to prevent hematoma formation and pain we also prefer bandages after surgical or endovenous vein procedures, using cohesive or adhesive material, or in combination with local pressure pads.

There are no definitive data on the superiority of a certain bandaging technique (spiral, figure of eight, circular etc). However, important features of good compression bandages are the development of sufficiently high pressure peaks during walking enabling intermittent compression of the veins and a tolerable resting pressure. The high pressure amplitudes correspond to a strong massaging effect during walking (Fig 2). The bandages should stay in place for several days and nights and will 

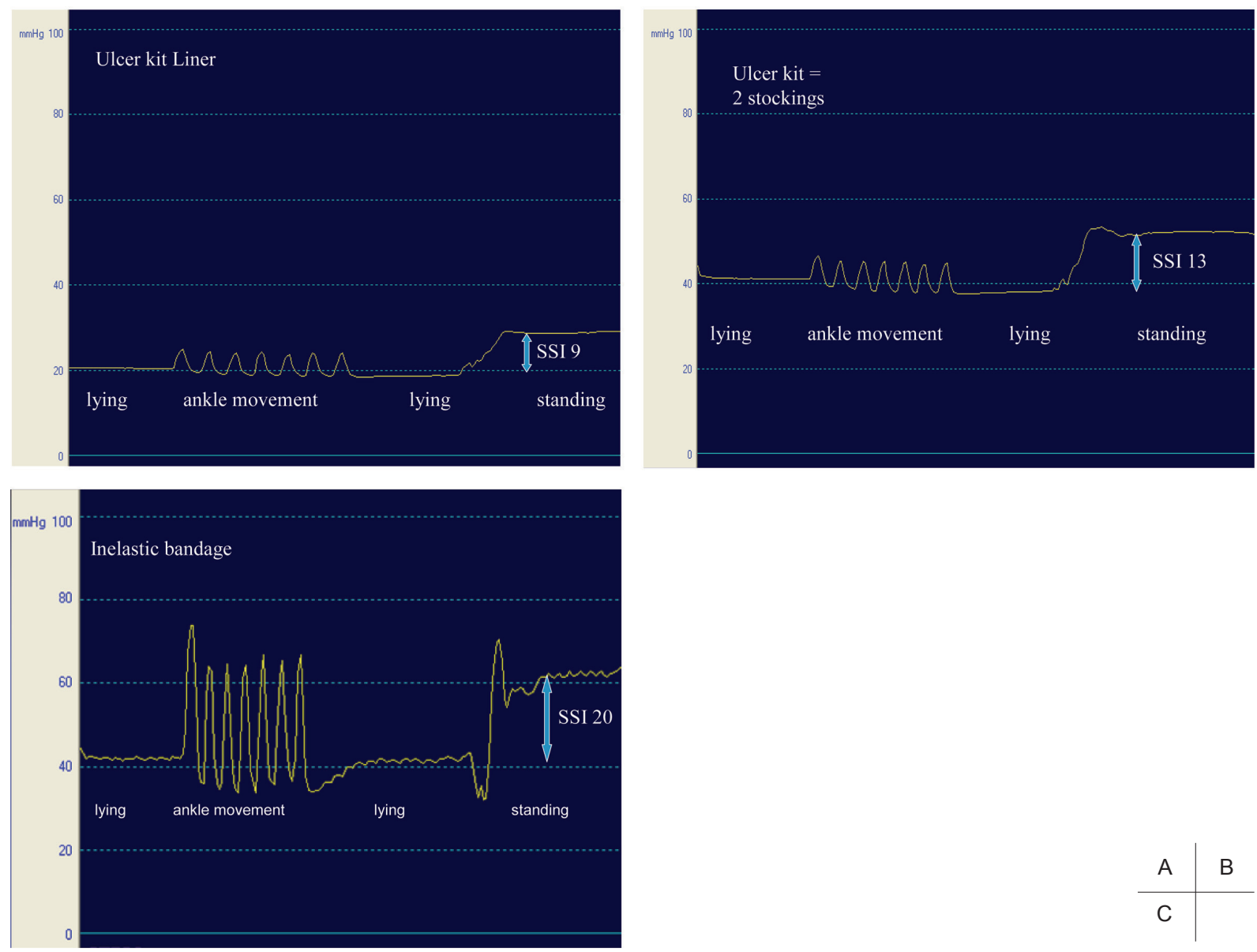

Fig. 2 Registration of compression pressure of different compression materials measured at the B1-point (about $12 \mathrm{~cm}$ above the inner ankle). a: under the "liner" of a medi ulcer kit ${ }^{\circledR}$ (double stocking). b: after putting the second stocking over the liner. c: under an inelastic bandage (Rosidal sys $\left.{ }^{\circledR}\right)$. Dorsiflexions (ankle movement) in the lying position induce intermittent pressure waves corresponding to a massaging effect. The pressure rises by standing up: SSI= static stiffness index = pressure difference standing - lying. Note that the inelastic bandage and the double stocking exert both the same resting pressure of $40 \mathrm{mmHg}$. However, the pressure amplitudes during dorsiflexions and SSI are much higher under the inelastic bandage than under the double stocking.

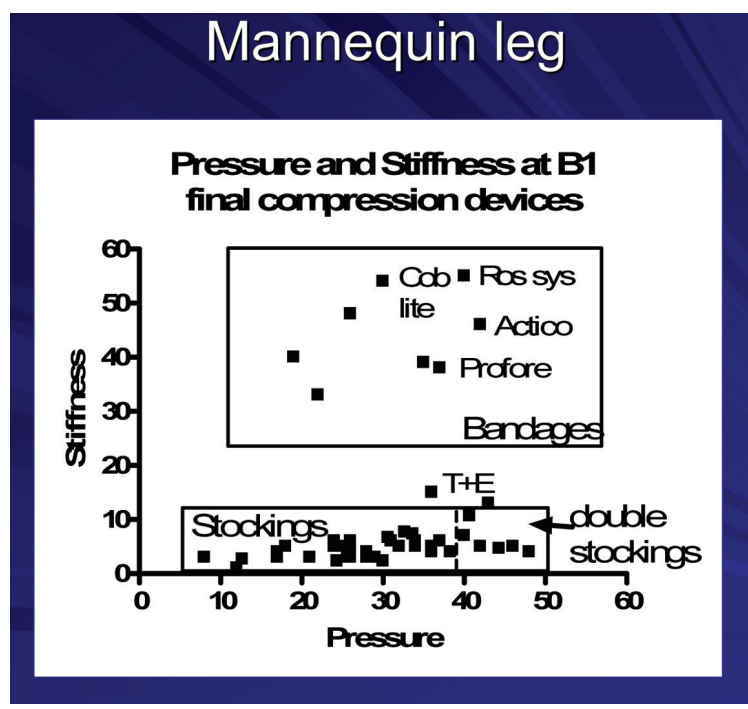

Fig. 3 Pressure measurements on the mannequin leg. ${ }^{6)}$ Compression pressure (x-axis) and stiffness (= pressure after enlarging the circumference of the model by $1 \mathrm{~cm}$, y-axis) measured under different stockings and bandages at B1 of the model leg. The pressure of the tested single layer stockings was between $\sim 10$ and $\sim 40 \mathrm{mmHg}$, for double stockings between 40 and $50 \mathrm{mmHg}$, maximal stiffness values did rarely exceed $10 \mathrm{mmHg}$. The multi-component bandages tested were in a comparable range showing resting pressures between 20 and $40 \mathrm{mmHg}$, but much higher stiffness values. (Cob lite $=$ Coban lite ${ }^{\circledR}$, Ros sys $=$ Rosidal sys ${ }^{\circledR}, \mathrm{T}+\mathrm{E}=$ Tubulcus ${ }^{\circledR}+$ elastic bandage) 
Table 1 Pressure ranges for bandages measured in the medial gaiter region in the supine position ${ }^{5}$

\begin{tabular}{cc}
\hline Proposed terms & $\mathrm{mmHg}$ at B1 \\
\hline mild & $<20$ ("mild") \\
medium & $20-<40$ ("medium") \\
strong & $40-<60$ ("strong") \\
very strong & $\geq 60$ ("very strong") \\
\hline
\end{tabular}

Table 2 Indications for which the use of medical compression stockings could be proven by evidence based medicine ${ }^{3)}$

Light compression stockings $(<20 \mathrm{~mm} \mathrm{Hg})$

Medical compression stockings $(20-30 \mathrm{mmHg})$

Medical compression stockings $(30-40 \mathrm{mmHg})$
Improvement of venous symptoms in patients with CEAP C0s-C1s and in varicose veins of pregnancy

Prevention of leg swelling related to prolonged sitting and standing ("occupational leg oedema")

Prevention of venous thromboembolism in bed-ridden patients especially after general surgery

Better results and less adverse outcome after sclerotherapy of small teleangiectasias (C1)

Improvement of subjective symptoms in varicose veins of pregnancy

Less pain and swelling in the acute phase of deep vein thrombosis

Less side-effects after sclerotherapy of large veins (C2) compared to light bandages

Reduction of lipodermatosclerotic areas on the leg (C4b)

Improved healing of venous leg ulcers (C6)

Prevention of ulcer recurrence, higher pressure ranges seem to be superior

Prevention of PTS after proximal DVT

Maintenance therapy in lymphoedema lose initial pressure considerably. However, it could be shown that despite this pressure loss, which is mainly due to oedema reduction, they will maintain their positive effect on the calf muscle pump function. ${ }^{7)}$ Because of economic reasons, bandages should be preferably washable and reusable. ${ }^{8)}$

Multi-component bandages better meet the above requirements than single- component bandages. In order to increase the local pressure over the treated venous segment following sclerotherapy or over a venous ulcer situated behind the medial malleolus, pads or rolls made of different material may be used. The increase of local pressure under a pad is the consequence of Laplace's law explaining that the pressure of a compression device around a cylinder is directly proportional to the force of application and indirectly proportional to the radius of the cylinder.

Thigh compression may be performed by using adhesive bandage material (e.g. Panelast $\left.{ }^{\circledR}\right)$. After endovenous treatment of thigh veins local pressure can be increased by using special pads. ${ }^{9)}$

\section{Practical Use of Compression Stockings}

Stockings should only be prescribed if they can be applied on a regular basis. Different devices have been developed to facilitate the application of stockings which should be donned in the morning. New stockings should be prescribed after 3-6 months if used daily. Main indications for wearing compression stockings are the prevention and therapy of oedema, after active treatment of varicose veins, lipodermatosclerosis and the maintenance treatment after leg ulcers have been healed, after deep vein thrombosis in order to prevent post-thrombotic syndrome, and in patients with lymphoedema to maintain the oedema reduction achieved by bandages.

Table 2 summarizes indications for which medical compression stockings have been shown beneficial by clinical studies fulfilling the criteria of evidence based medicine. ${ }^{3)}$

There are still indications for which clear, beneficial effects of compression stockings could not yet been proved by randomized, controlled trials, which does not mean 
Table 3 Effects of compression therapy

\begin{tabular}{ll}
\hline Parameter & Investigative method (Examples) \\
\hline Sub-bandage pressure & MST-tester ${ }^{\circledR}$, Kikuhime ${ }^{\circledR}$, Picopress ${ }^{\circledR}$, AMI ${ }^{\circledR}$ Japan \\
Reduction of edema & Volumetry, isotopes, ultrasound, MRI \\
Reduction of venous volume & Phlebography, blood pool scintigraphy, \\
& Air plethysmography (APG), MRI \\
Increased venous velocity & Circulation time (isotopes), Duplex \\
Blood shift into central compartments & Blood pool scintigraphy, cardiac output \\
Decreased venous reflux & Duplex, APG \\
Improved venous pump & Foot volumetry, plethysmography, venous pressure \\
Decreased arterial flow (very strong compression) & Duplex, Xenon-clearance, Laser Doppler \\
Increased arterial flow (moderate and intermittent compression) & Nuclear magnetic flowmetry, Laser Doppler, tcPO2 \\
Effect on microcirculation & Capillaroscopy, tcPO2, Laser Doppler \\
Increased lymphatic drainage & Isotopic and indirect lymphography, indocyanin green \\
Effect on ultrastructure and cytokines & Microscopy and histochemistry, laboratory invstigations \\
\hline
\end{tabular}

that they might not be efficient:

- Prevention of progression or complications in asymptomatic or symptomatic varicose veins.

- prevention of varicose veins after surgery

- dose response relationship between optimal compression pressure and oedema reduction. ${ }^{10)}$

\section{Quality of Life and Compliance}

Several studies have shown an improvement in quality of life with compression treatment. Compliance is crucial in preventing ulcer recurrence. ${ }^{3)}$ It has been shown that after DVT regular daily use of compression stockings for at least two years can reduce the incidence and severity of post-thrombotic syndrome. ${ }^{11)}$

\section{Mode of Action}

Some beneficial effects of compression treatment and methods used to measure these effects are summarized in Table 3. A high SSI-value characterizes an "intelligent bandage" which is comfortable in the resting position but will increase the compression pressure just by standing up, thereby compensating the increased intravenous hydrostatic pressure. Compression acts most effectively when it is combined with movement. During walking, non-yielding stiff material will exert a massaging effect to the leg, thereby intermittently blocking venous reflux and increasing the expelled volume of the calf pump resulting in a reduction of ambulatory venous hypertension. ${ }^{12}$

\section{"Evidence Based" Compression}

The evidence evolving from different RCTs and meta-analyses seems occasionally contradictory. This is mainly due to the fact that therapeutic interventions are often ill defined, e.g., comparing good stockings with poor bandages. The dosage of compression (pressure and stiffness) is rarely declared so that the conclusions drawn may be misleading.

Recent experimental studies have questioned some conventional concepts on compression ${ }^{13)}$ :

- Thigh length stockings are able to reduce the calibre of the femoral vein in spite of a very low pressure at mid-thigh level ( $6 \mathrm{mmHg}$ ) (Fig. 4). ${ }^{14)}$.

- Compression of superficial and deep veins depends very much on the body position: in the horizontal prone position and in standing deep veins are mostly more affected than superficial veins ${ }^{14)}$ (Fig. 5). This means that in the upright position pressures over $40 \mathrm{mmHg}$ are needed to compress a superficial vein (e.g. after therapeutic procedure), while much less pressure may already reduce the diameter of deep veins. ${ }^{15)}$

- Higher pressure over the calf leads to a stronger effect on the venous pump than a pressure gradient. ${ }^{16)}$

- In chronic venous oedema lower pressure may be more effective concerning volume reduction than very high pressure. ${ }^{10)}$

- In lymphoedema of the lower extremities inelastic two- component bandages may reduce oedema more effectively compared to multicomponent bandages applied with the same pressure, probably due to less restriction of movement. ${ }^{17)}$

- Not only intermittent pressure waves ${ }^{18)}$ but also sustained pressure up to $40 \mathrm{mmHg}$ improve arterial flow, both in normals and patients with arterial occlusive disease, e.g. in patients with mixed, arterial-venous leg ulcers. ${ }^{19)}$

In contrast to drug therapy compression treatment had never to pass any pharmacological phase I and phase II trials to confirm clinical efficacy and determine the therapeutic dose range. Although some insight concerning the mechanisms of action of compression has emerged from 


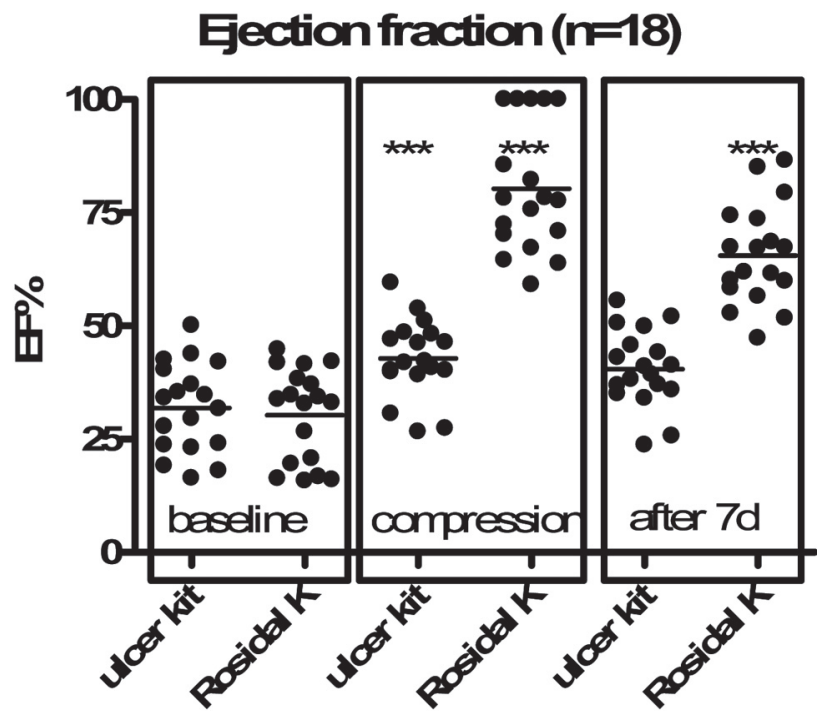

Fig. 4 Measurement of the ejection fraction of the calf pump using strain gauge plethysmography in 18 patients with severe venous insufficiency. The baseline values are reduced (normal values $>60 \%$ ) (left) but show an immediate increase after compression (***p $<0.001$ compared to baseline) (middle). Repeating the test one week later with stockings (ulcer kit) or inelastic bandages still on the leg (right), EF is still significantly increased under bandages but not under stockings, in spite of the pressure loss being much higher under bandages than under stockings. ${ }^{7)}$

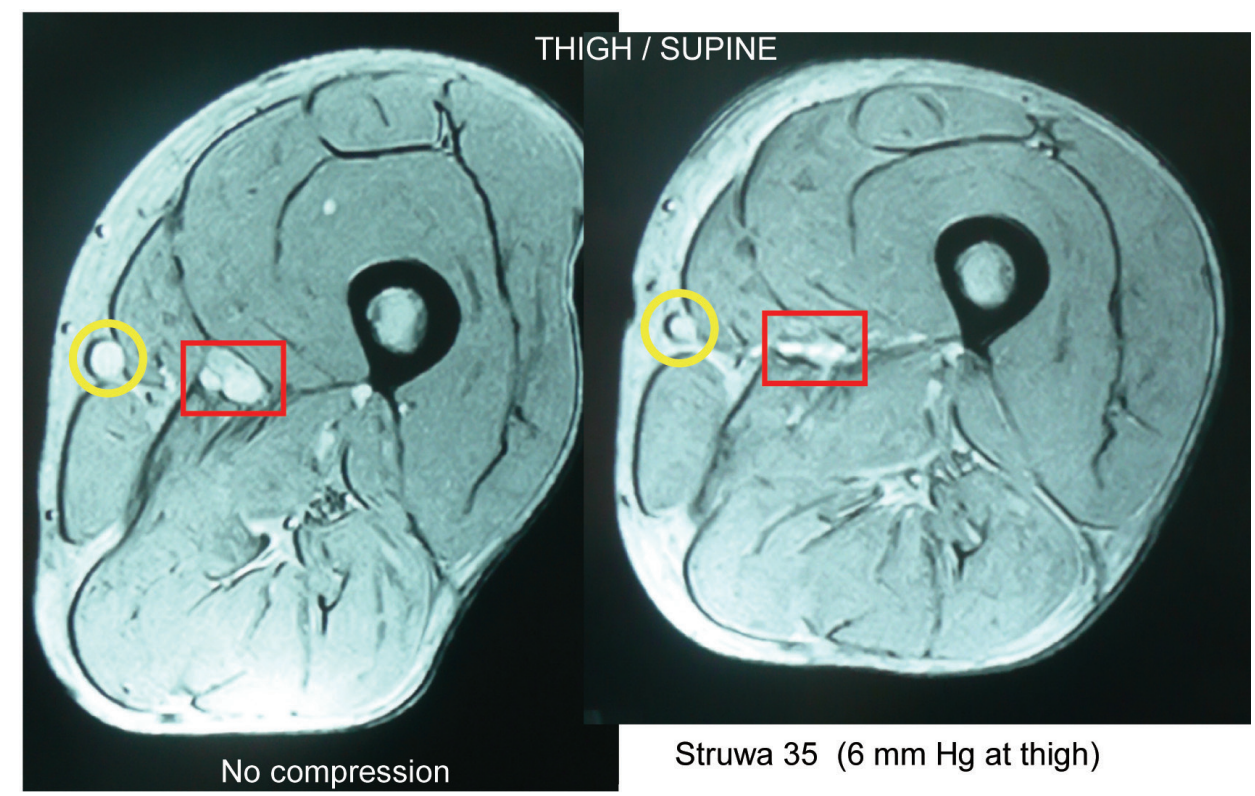

Fig. 5 MRI mid-thigh cross section in supine position, left without compression, right wearing a compression stocking which exerted a very low pressure $(6 \mathrm{mmHg})$ at thigh level. The stocking leads to a change of the configuration of the thigh becoming more circular and to a clear narrowing of superficial (marked by a circle) and deep veins (marked by rectangle). $\left.{ }^{9}\right)$

several studies during the last years, a lot more has to be learned in order to tailor and to optimize this important treatment modality to different clinical indications and to satisfy our patients.

\section{Disclosure Statement}

No disclosures to declare.

\section{ReferenCes}

1) Partsch H, Rabe E, Stemmer R. Compression therapy of the extremities. Editions Phlebologiques Francaises, Paris 1999.

2) Vin F, Benigni JP. International Union of Phlebology, et al Compression therapy. International Consensus Document Guidelines according to scientific evidence. Int Angiol 2004; 23: 317-45. [Medline] 
3) Partsch H, Flour M, Smith PC, et al. Indications for compression therapy in venous and lymphatic disease consensus based on experimental data and scientific evidence. Under the auspices of the IUP. Int Angiol 2008; 27: 193-219. [Medline]

4) Partsch H, Clark M, Bassez S, et al. Measurement of lower leg compression in vivo: recommendations for the performance of measurements of interface pressure and stiffness: consensus statement. Dermatol Surg 2006; 32: 224-32, discussion 233. [Medline] [CrossRef]

5) Partsch H, Clark M, Mosti G, et al. Classification of compression bandages: practical aspects. Dermatol Surg 2008; 34: 600-9. [Medline] [CrossRef]

6) Hirai M, Niimi K, Miyazaki K, et al. Development of a device to determine the stiffness of elastic garments and bandages. Phlebology 2011; 26: 285-91. [Medline] [CrossRef]

7) Mosti G, Partsch H. Inelastic bandages maintain their hemodynamic effectiveness over time despite significant pressure loss. J Vasc Surg 2010; 52: 925-31. [Medline] [CrossRef]

8) Wong IK, Andriessen A, Lee DT, et al. Randomized controlled trial comparing treatment outcome of two compression bandaging systems and standard care without compression in patients with venous leg ulcers. J Vasc Surg 2012; 55: 1376-85. [Medline] [CrossRef]

9) Partsch H, Mosti G. Thigh compression. Phlebology 2008; 23: 252-8. [Medline] [CrossRef]

10) Partsch H, Damstra RJ, Mosti G. Dose finding for an optimal compression pressure to reduce chronic edema of the extremities. Int Angiol 2011; 30: 527-33. [Medline]

11) Musani MH, Matta F, Yaekoub AY, et al. Venous compression for prevention of posthrombotic syndrome: a meta-analysis. Am J Med 2010; 123: 735-40. [Medline] [CrossRef]
12) Partsch H. Improving the venous pumping function in chronic venous insufficiency by compression as dependent on pressure and material. VASA 1984; 13: 58-64. [Medline]

13) Flour M, Clark M, Partsch H, et al. Dogmas and controversies in compression therapy: Report of an International Compression Club (ICC) meeting, Brussels, May 2011. Int Wound J. 2012. [CrossRef] [Epub ahead of print]. [Medline]

14) Partsch H, Mosti G, Mosti F. Narrowing of leg veins under compression demonstrated by magnetic resonance imaging (MRI). Int Angiol 2010; 29: 408-10. [Medline]

15) Partsch H, Mosti G, Uhl JF. Unexpected venous diameter reduction by compression stocking of deep, but not of superficial veins. Veins and Lymphatics 2012; 1: e3 [CrossRef].

16) Mosti G, Partsch H. Compression stockings with a negative pressure gradient have a more pronounced effect on venous pumping function than graduated elastic compression stockings. Eur J Vasc Endovasc Surg 2011; 42: 261-6. [Medline] [CrossRef]

17) Lamprou DA, Damstra RJ, Partsch H. Prospective, randomized, controlled trial comparing a new twocomponent compression system with inelastic multicomponent compression bandages in the treatment of leg lymphedema. Dermatol Surg 2011; 37: 985-91. [Medline] [CrossRef]

18) Kalodiki E, Giannoukas AD. Intermittent pneumatic compression (IPC) in the treatment of peripheral arterial occlusive disease (PAOD)--A useful tool or just another device? Eur J Vasc Endovasc Surg 2007; 33: 309-10. [Medline] [CrossRef]

19) Mosti G, Iabichella ML, Partsch H. Compression therapy in mixed ulcers increases venous output and arterial perfusion. J Vasc Surg 2012; 55: 122-8. [Medline] [CrossRef] 